\title{
Postoperative self-efficacy and psychological morbidity in radical prostatectomy ${ }^{1}$
}

\author{
Luciana Regina Ferreira da Mata $^{2}$ \\ Emilia Campos de Carvalho ${ }^{3}$ \\ Cássia Regina Gontijo Gomes ${ }^{4}$ \\ Ana Cristina da Silva ${ }^{5}$ \\ Maria da Graça Pereira ${ }^{6}$
}

Objective: evaluate the general and perceived self-efficacy, psychological morbidity, and knowledge about postoperative care of patients submitted to radical prostatectomy. Identify the relationships between the variables and know the predictors of self-efficacy. Method: descriptive, cross-sectional study, conducted with 76 hospitalized men. The scales used were the General and Perceived Self-efficacy Scale and the Hospital Anxiety and Depression Scale, in addition to sociodemographic, clinical and knowledge questionnaires. Results: a negative relationship was found for self-efficacy in relation to anxiety and depression. Psychological morbidity was a significant predictor variable for self-efficacy. An active professional situation and the waiting time for surgery also proved to be relevant variables for anxiety and knowledge, respectively. Conclusion: participants had a good level of general and perceived self-efficacy and small percentage of depression. With these findings, it is possible to produce the profile of patients about their psychological needs after radical prostatectomy and, thus, allow the nursing professionals to act holistically, considering not only the need for care of physical nature, but also of psychosocial nature.

Descriptors: Prostatectomy; Anxiety; Depression; Self Efficacy.

\footnotetext{
${ }^{1}$ Paper extracted from doctoral dissertation "Effectiveness of a teaching program for home care of patients undergoing to radical prostatectomy: randomized clinical trial", presented to Escola de Enfermagem de Ribeirão Preto, Universidade de São Paulo, PAHO/WHO Collaborating Centre for Nursing Research Development, Ribeirão Preto, SP, Brazil. Supported by Conselho Nacional de Desenvolvimento Científico e Tecnológico (CNPq), Brazil, process \# 141377/2010-0.

2 PhD, Adjunct Professor, Campus Centro Oeste Dona Lindu, Universidade Federal de São João del Rei, Divinópolis, MG, Brazil.

3 PhD, Full Professor, Escola de Enfermagem de Ribeirão Preto, Universidade de São Paulo, PAHO/WHO Collaborating Centre for Nursing Research Development, Ribeirão Preto, SP, Brazil.

${ }^{4}$ Master's student, Departamento de Enfermagem, Universidade Federal de São Carlos, São Carlos, SP, Brazil.

${ }^{5}$ RN, Instituto de Previdência, Polícia Militar de Minas Gerais, Lavras, MG, Brazil.

${ }^{6}$ PhD, Associate Professor, Escola de Psicologia, Universidade do Minho, Braga, Portugal.
}

Corresponding Author:

Emilia Campos de Carvalho

Universidade de São Paulo. Escola de Enfermagem de Ribeirão Preto

Departamento de Enfermagem Geral e Especializada

Av. Bandeirantes, 3900

Bairro: Monte Alegre

CEP: 14040-902, Ribeirão Preto, SP, Brasil

E-mail: ecdcava@usp.br
Copyright @ 2015 Revista Latino-Americana de Enfermagem This is an Open Access article distributed under the terms of the Creative Commons Attribution Non-Commercial License (CC BY-NC).

This license lets others distribute, remix, tweak, and build upon your work non-commercially, and although their new works must also acknowledge you and be non-commercial, they don't have to license their derivative works on the same terms. 


\section{Introduction}

Radical prostatectomy is the standard surgery for patients with prostate cancer (PC) in potentially treatable stages, consisting of removal of prostate and seminal vesicles ${ }^{(1)}$. After surgery, patients may present with different symptoms that include painful bladder spasms, fatigue, decreased physical function, infection in the urinary tract and surgical site, constipation, sexual impotence, and urinary incontinence ${ }^{(2)}$.

Lack of knowledge about how the recovery will be and how to perform self-care at home can have a significant impact on healthy postoperative recovery, and is also one of the reasons that trigger psychological morbidity(3). Psychological morbidity, i.e., anxiety and depression, are the psychiatric disorders most commonly associated with clinical illness ${ }^{(4)}$. Regarding PC, many men experience, concomitantly, high levels of both anxiety and depression after the diagnosis of localized $\mathrm{PC}(5,6)$ and, depending on the type of treatment to be conducted, may have uncomfortable side effects, generating long lasting impact on the physical and psychological well-being ${ }^{(2,7)}$.

According to data in the literature, PC is considered the cancer of the elderly, because its incidence is more common in men over the age of 60 years ${ }^{(8,9)}$. With aging, people need to change, even more, the social attitudes and the practices for the conduct of healthy aging and maintenance of self-efficacy. The maintenance of cognitive functioning and learning ability in old age is directly related to maintaining the sense of self-efficacy, education level, and a physically active lifestyle ${ }^{(10)}$.

Self-efficacy is a component of motivation, since it is a performance evaluation, which is fundamental for the acquisition and change in behavior ${ }^{(11)}$. Different selfefficacy levels can increase or decrease the motivation to act. Individuals with high self-efficacy, usually, tend to perform more challenging tasks, invest more effort and persistence than those with low self-efficacy ${ }^{(1,6)}$.

Knowing the patient's self-efficacy in the radical prostatectomy postoperative period is important(6), since this construct influences the choices of action to be performed, the effort of the patient in reaching goals, in overcoming obstacles and failures, stress, anxiety and depression and, finally, in the level of sense of achievement they experience ${ }^{(12,13)}$.

Patient education in the postoperative period is essential to provide the individual with adequate knowledge for self-care in the home environment and, thus, reduce the occurrence of complications after discharge, improving recovery, enhancing the ability to conduct self-care and improving quality of life ${ }^{(2,14)}$. The ability to manage their own care has implicit the selfefficacy construct, defined as the personal conviction to successfully execute an action, producing desired results in a given situation. This concept is considered an important factor in therapeutic changes ${ }^{(1)}$.

In fact, men with PC need physical and psychological support to deal with the symptoms and adapt to the new life during the period of recovery from radical prostatectomy ${ }^{(6,7)}$. The health team responsible for care is an important element of support in this context. As part of this team, the nurse is responsible for planning and implementing a training on care after hospital discharge directed to the patient, providing guidance as the care requires ${ }^{(14,15)}$, always considering as guiding questions for the training the stimulus to his ability to manage care, specificity of the problems, and psychological needs ${ }^{(16)}$.

Therefore, it is of interest to know the characteristics of the patient with PC, submitted to radical prostatectomy, analyze his self-efficacy, psychological morbidity, and knowledge on home care, trying to inform the staff of surgical clinics - that provide assistance to these individuals - on their main needs, that go beyond the sphere of care of physical nature.

Thus, the aim of this study is to evaluate the general and perceived self-efficacy, psychological morbidity (anxiety and depression), and knowledge on postoperative care of patients submitted to radical prostatectomy, as well as to identify possible relationships between the variables and predictors of self-efficacy in the sample under study. In this sense, a negative relationship is expected between the variables self-efficacy and psychological morbidity, while a positive relationship is expected between self-efficacy and knowledge. Regarding predictors, psychological morbidity is expected to be a negative predictor for selfefficacy, while knowledge is expected to be a positive predictor for self-efficacy.

\section{Method}

\section{Procedure and sample}

This is a descriptive, cross-sectional study conducted with 76 men admitted for surgical treatment of PC to two hospitals in the countryside of the state of Minas Gerais, Brazil, between January and December 2012. Participants were selected based on the criteria: aged 18 or more; hospitalized to undergo surgery for 
total removal of the prostate; not in critical condition; and have cognitive ability to participate (application of the Mini-Mental State Examination) ${ }^{(17)}$. The study was submitted to approval of the Research Ethics Committee of the São João de Deus Hospital (assessment No. 42/2011). Data collection was carried out by the researchers on the second day after surgery through individual interviews and by referring to medical records of the participants.

Sample size was defined by the $Z$ statistical test, of normal distribution, estimating a ratio relative to the population of interest for a significance level of $5 \%$ and sample power of $80 \%$, resulting in a minimum size of 68 patients.

\section{Instruments}

- Sociodemographic (sex, age, education, marital status and employment status) and clinical questionnaire (knowledge or no knowledge about diagnosis, waiting time for surgery, type of surgery, and presence of comorbidities).

- General and perceived self-efficacy scale ${ }^{(18)}$, adapted and validated for application in Brazil(19), which predicts an individual's ability to overcome the daily difficulties, as well as adaptation after experiencing all sorts of life's stressful events. It consists of 10 items with answers in Likert-like scale, ranging from one to five. Each item refers to the achievement of goals and indicates a stable internal attribution of success, and the higher the result, the greater the perception of self-efficacy. Cronbach's alpha coefficient, in this sample, was 0.7.

- Hospital Anxiety and Depression Scale(20), version in Portuguese $^{(21)}$. The HADS scale contains 14 questions of the multiple choice type, with two subscales, for anxiety and depression, with seven items each. It contains 14 Likert-like questions, with two subscales, one for anxiety and the other for depression, with seven items each. Each question has four options for answer, with values ranging from zero to three. The overall score for each subscale ranges from zero to 21 , and the higher the value, the greater the emotional disorder. The authors suggest the value eight as cutoff point, considering lower values as absence of anxiety and depression. Cronbach's alpha coefficient, in this sample, was 0.9.

- Questionnaire of "Knowledge about postoperative home care in radical prostatectomy", prepared for this study, includes 23 questions, with options for answers "right", "wrong", and "do not know", enabling to evaluate the patients' knowledge about the postoperative care in radical prostatectomy (care concerning the surgical incision and urinary catheter; urinary incontinence, exercises for pelvic muscles, care as for physical exercises, food, and consumption of liquids; bowel movements; complication signs; and erection problems). For each correct answer, a point is attributed, totaling a maximum of 23 points. A high score indicates great knowledge about postoperative care. Cronbach's alpha coefficient, in this study, was 0.7.

\section{Data analysis}

Data were processed and analyzed using the Statistical Package for Social Sciences (SPSS) version 20.0. For descriptive analysis of the data, we used mean and median position measurements, and of Standard Deviation (SD) variability for continuous variables, and simple frequency for categorical variables. In order to identify possible relationships between the variables self-efficacy, anxiety, depression, and knowledge about postoperative care, we used the Pearson correlation test. The powers of the correlations were analyzed based on the classification $^{(22)}$ of values below 0.3 - even if statistically significant - as of weak magnitude and useless in clinical practice, values between 0.3 and 0.5 as of moderate magnitude, and values above 0.5 as of strong magnitude.

To test differences in the variables self-efficacy, anxiety, depression and knowledge in relation to waiting time for surgery, employment status, knowledge of the diagnosis of PC, and marital status, we used the student $t$ test for independent samples. To test differences in relation to education, participants were subdivided into three groups and one-factor analysis of variance (ANOVA) was used. Finally, to know the variables that are predictors of self-efficacy, a multiple linear regression (method enter) was conducted.

\section{Results}

\section{Sociodemographic and clinical characterization of the sample}

The sample of this study consisted of 76 participants, whose average age was 64.2 years $(S D=6.6)$, ranging between 49 and 75 years, and subsequently they were grouped into two categories: aged 65 years or less (53.9\%) and over $65(46.1 \%)$. Most were married or in a stable relationship (84.2\%), followed by the unmarried $(7.9 \%)$, widowed $(3.9 \%)$, and divorced (3.9\%). Average education was six years $(S D=4.8)$, being grouped 
into three categories: zero to four years of education $(60.5 \%)$, five to 10 years (18.4\%), and 11 years or more $(21.1 \%)$. As for employment status, $64.5 \%$ were active and $35.5 \%$ were not active. Average individual monthly income was BRL $2029(S D=1240)$ and average family monthly income was BRL 2759 (SD=1863).

Regarding clinical data, $77.6 \%$ of participants had knowledge of the diagnosis of PC; $18.4 \%$ awaited surgical treatment for less than one month, $43.4 \%$ between one and three months, $31.6 \%$ between 4 and 12 months, and $6.6 \%$ for more than one year. The prevalent comorbidities among participants were: hypertension $(52.6 \%)$, heart disease $(14.5 \%)$, and diabetes mellitus $(11.8 \%)$.

The result obtained by the General and Perceived Self-efficacy Scale indicated average of $39.0(\mathrm{SD}=6.4)$. For anxiety, we found an average value of $7.7(S D=5.7)$, and, for depression, an average of $4.0 \quad(S D=3.8)$. According to the Scale's cutting point, $31.6 \%$ showed anxiety and only $0.5 \%$ showed depression. Regarding knowledge about postoperative care, average of correct answers for the 23 questions was $11.6(S D=3.2)$.
Relationship between self-efficacy, anxiety, depression, and knowledge about postoperative care

By analyzing the presence of possible relationships between the variables, there was a strong positive correlation between anxiety and depression ( $r=0.6$; $\mathrm{p} \leq 0.000)$; moderate negative correlation for selfefficacy in relation to anxiety $(r=-0.3 ; p \leq 0.002)$ and in relation to depression $(r=-0.5 ; p \leq 0.000)$.

Differences in self-efficacy, anxiety, depression, and knowledge about postoperative care in relation to waiting time, age, employment status, education, marital status, and knowledge of diagnosis

Significant differences of knowledge about postoperative care were found in relation to waiting time and to anxiety in relation to employment status. Thus, patients with waiting time equal to or less than three months had greater knowledge about postoperative care, and those who were employed showed higher anxiety levels (Table 1).

Table 1 - Results for student t test for differences in self-efficacy, anxiety, depression, and knowledge about postoperative care in relation to waiting time, age, employment status, education, marital status, and knowledge of diagnosis. Divinópolis, MG, Brazil, 2012

\begin{tabular}{|c|c|c|c|c|c|c|c|c|}
\hline \multirow{2}{*}{ Variables } & \multicolumn{2}{|c|}{ Self-efficacy } & \multicolumn{2}{|c|}{ Anxiety } & \multicolumn{2}{|c|}{ Depression } & \multicolumn{2}{|c|}{ Knowledge } \\
\hline & Mean (SD) & $p^{*}$ & Mean (SD) & $p^{*}$ & Mean (SD) & $p^{*}$ & Mean (SD) & $p^{*}$ \\
\hline \multicolumn{9}{|l|}{ Waiting time } \\
\hline 0 to 3 months $(n=45)$ & $38.9(5.9)$ & 0.984 & $7.4(5.9)$ & 0.703 & $4.5(4.1)$ & 0.255 & $12.2(2.9)$ & $0.037^{*}$ \\
\hline 4 months or more $(n=28)$ & $38.9(7.4)$ & & $7.9(5.5)$ & & $3.4(3.4)$ & & $10.6(3.5)$ & \\
\hline Age & & 0.794 & & 0.154 & & 0.941 & & 0.748 \\
\hline 65 or less $(n=39)$ & $38.7(7.2)$ & & $8.5(6.0)$ & & $4.1(4.2)$ & & $11.7(2.9)$ & \\
\hline 65 or more $(n=45)$ & $39.1(5.8)$ & & $6.6(5.3)$ & & $4.1(3.5)$ & & $11.5(3.5)$ & \\
\hline \multicolumn{9}{|l|}{ Employment status } \\
\hline Employed $(n=49)$ & $39.2(7.1)$ & 0.823 & $8.8(5.3)$ & $0.034^{*}$ & $3.8(3.7)$ & 0.559 & $11.6(2.7)$ & 0.984 \\
\hline Not employed $(n=27)$ & $38.8(5.2)$ & & $5.9(5.9)$ & & $4.3(4.1)$ & & $11.6(4.1)$ & \\
\hline \multicolumn{9}{|l|}{ Knowledge of diagnosis } \\
\hline Knows $(n=59)$ & $38.7(6.4)$ & 0.412 & $7.8(5.8)$ & 0.866 & $4.1(3.8)$ & 0.766 & $11.9(3.3)$ & 0.078 \\
\hline Does not know $(n=17)$ & $40.9(6.7)$ & & $7.5(5.3)$ & & $3.4(3.9)$ & & $10.5(2.6)$ & \\
\hline \multicolumn{9}{|l|}{ Marital status } \\
\hline $\begin{array}{l}\text { Unmarried, widowed, divorced } \\
(\mathrm{n}=12)\end{array}$ & $38.8(6.8)$ & 0.305 & $7.9(5.6)$ & 0.589 & $4.0(3.7)$ & 0.976 & $11.8(3.1)$ & 0.183 \\
\hline $\begin{array}{l}\text { Married/common-law marriage } \\
(n=64)\end{array}$ & $40.3(4.1)$ & & $6.9(6.3)$ & & $3.9(4.5)$ & & $10.4(4.0)$ & \\
\hline
\end{tabular}

$* \mathrm{p} \leq 0.05$

For the variable education (zero to four years, five to 10 years, 11 years or more) based on the ANOVA, no significant differences were found for the variables self-efficacy, anxiety, depression, and knowledge about postoperative care.

\section{Predictors of self-efficacy}

Results revealed that psychological morbidity (anxiety and depression) is a significant predictor variable of self-efficacy, explaining $14.2 \%$ of the variance, as shown in Table 2 . Thus, the lower the psychological morbidity, the greater the self-efficacy. 
Table 2 - Predictors of self-efficacy in patients submitted to radical prostatectomy $(n=76)$. Divinópolis, MG, Brazil, 2012

\begin{tabular}{|c|c|c|c|c|c|c|}
\hline \multirow{2}{*}{ Variables } & \multicolumn{3}{|c|}{ Block I* } & \multicolumn{3}{|c|}{ Block II $^{\dagger}$} \\
\hline & $\beta$ & $\mathbf{t}$ & Sig. & $\beta$ & $\mathbf{t}$ & Sig. \\
\hline Age & 0.1 & 0.9 & 0.4 & & & \\
\hline Marital status & 2.0 & 0.9 & 0.4 & & & \\
\hline Knowledge of diagnosis & -2.3 & -1.1 & 0.3 & & & \\
\hline Psychological morbidity & & & & 0.1 & -3.4 & $0.001^{\ddagger}$ \\
\hline Knowledge about postoperative care & & & & 0.2 & 0.2 & 0.880 \\
\hline $\mathrm{R}^{2}$ & & 0.1 & & & 0.2 & \\
\hline $\mathrm{R}^{2}$ adjusted & & 0.0 & & & 0.1 & \\
\hline
\end{tabular}

* Sociodemographic and clinical variables

† Psychological variables

$\neq \mathrm{p} \leq 0.01$

\section{Discussion}

Prostatic alterations, including PC, are considered characteristic pathologies of men aged over 60 years, considering that aging is a risk factor for prostate enlargement. The average age in this study (64.2 years, $\mathrm{SD}=6.6$ ) corroborates the literature data. Approximately three-quarters of the cases of benign or malignant hyperplasia occur between 60 and 65 years of age ${ }^{(9)}$ and more than $70 \%$ of the cases of PC occur in men over 70 years of age ${ }^{(23)}$.

Regarding the clinical characterization of the sample, we considered as major comorbidities hypertension $(52.6 \%)$, heart disease $(14.5 \%)$, and diabetes mellitus $(11.8 \%)$. Diet rich in saturated fat, red meat, milk, and low in fiber and vitamins is a risk factor for development of PC, as well as of the comorbidities identified(23). However, this type of cancer is related, primarily, to the genetic factor, first-degree relatives having greater propensity to develop the disease, in a proportion eight times greater than for an individual with no first-degree relatives with $\mathrm{PC}(24)$.

In relation to psychological variables, $31.6 \%$ of patients had anxiety and $0.5 \%$, depression. In a study conducted with 100 patients submitted to different elective surgery in Brazil, similar values were found for anxiety (40.0\%) identified; however, the level of depression was higher $(22.0 \%)^{(15)}$. A possible explanation for the low level of depression in the sample under study can be related to the fact that $84.2 \%$ of the men were married or living in common-law marriage, a relationship already confirmed by German researchers, who claim that men in stable relationships have reduced levels of psychological alterations, when compared to those who live alone ${ }^{(3)}$. Furthermore, this disease is not associated with a high mortality risk(8), as other types of cancer, which may explain the low level of depression.

A study conducted in Holland followed patients with PC for five years, in the pre- and post-treatment period, and found a decrease in anxiety and depression after undergoing prostatectomy and radiotherapy. Average anxiety before surgery was 51.9 , down to 39.1 after 12 months (on a scale from 20 to 80, in which a higher score indicated a higher level of anxiety); and, for depression, from 16.8 down to 11.6 (on a scale from zero to 60 ). As for radiation therapy, prior to procedure, averages were 54.1 for anxiety and 19.9 for depression, down to 42.9 and 15.0 , respectively ${ }^{(5)}$.

It is known that lower levels of anxiety in the prostatectomy patient reflect positively on his mental health, and this may be associated with the development of better coping mechanisms to face stressing factors, facilitating the better management of postoperative physiological alterations(25).

Importantly, fear and uncertainty before the diagnosis of cancer and the side effects of treatment lead to psychological alterations and low self-efficacy. Since self-efficacy is the central belief that the individual has control over the events that can influence life, its reduction may adversely affect recovery, because, when control is lost, the desired results - such as the return to continence and sexual potency - cannot be achieved(6).

In this study, we found an average value of 39.0 points $(S D=6.4)$ in the General and Perceived Selfefficacy Scale (maximum score of 50). Similar results were found by Greek researchers, who evaluated the general self-efficacy of patients with different types of cancer, with an average of $31.9(\mathrm{SD}=6.0)$, in a scale of 40 points $^{(13)}$. The same study also found a negative correlation between general self-efficacy and anxiety, as in the sample studied. The authors evaluated general 
self-efficacy, anxiety, disease severity symptoms, and quality of life in cancer patients at the beginning of radiation therapy and one month after treatment. They found worsening of all outcomes assessed, in the preand post-treatment difference, and negative correlation between the absolute scores of general self-efficacy and anxiety. The authors justified the results by the fact that, often, patients are not prepared to deal with the physical, social and emotional changes that occur during the transition period between the discovery of the disease and the post-treatment phase ${ }^{(13)}$.

Another important finding was the psychological morbidity (anxiety and depression), which explained $14.2 \%$ of the variance, being a negative predictor of self-efficacy, i.e., patients with low anxiety and depression have higher self-efficacy. American researchers reaffirm this finding by finding that men with high self-efficacy are $45 \%$ less likely to have depression after radical prostatectomy ${ }^{(7)}$.

The hypothesis of the study stated that knowledge about operative care was a predictor of self-efficacy and it did not occur. It is believed that this result can be justified by the fact that almost half of patients (48.0\%) had knowledge about postoperative care.

In the present study, it is observed that patients in active employment status have higher level of anxiety $(p \leq 0.034)$. This fact can be explained by the inconvenience of the treatment in relation to working hours, fear arising from the uncertainty about the disease and recovery, and fear of losing the job, changing his financial condition, since many men in this age group are still active workers ${ }^{(10)}$.

Another important finding was the difference in the knowledge concerning postoperative care between the groups with different waiting times for surgery. Patients with waiting time from zero to three months had greater knowledge than the others $(p \leq 0.037)$. It is inferred that a reduced waiting time for surgical procedure triggers greater concern with health issues, with interest in solving the problem and increasing knowledge, thus favoring postoperative recovery, as the individual's expectation in relation to hospitalization, treatment and quality of care has a direct impact on this process ${ }^{(14)}$. However, it is a hypothesis that should be confirmed in future studies.

It is believed that patients seeking treatment and resolution of the problem in the shortest time are those that have greater concern for health and seek knowledge about the disease and treatment through different sources of information ${ }^{(26)}$. However, consideration should also be directed to the fact that the waiting time for surgery and, also, the postponement and rescheduling of the procedure can contribute to increased fear and feeling of distrust ${ }^{(15)}$.

Thus, educating the patient is essential to provide adequate knowledge for self-care in the home environment and, thus, reduce the occurrence of complications after discharge, improve recovery, enhance the ability of care, and minimize fear ${ }^{(27)}$.

Education and counseling are regular and indispensable items in the provision of care for men undergoing this type of surgery, both pre and postoperatively. These items should be directed to the provision of better information to prepare the patients for care in relation to the surgical wound and handling of indwelling urinary catheter at home; however, also prepare them to face the physical side effects, such as urinary incontinence and erectile dysfunction, and the consequent psychological suffering caused to the men and their wives ${ }^{(28,29)}$.

The following can be considered limitations of the study: the cross-sectional design, which does not allow the establishment of causal relationships between the variables analyzed; the data collection instrument used to assess knowledge, whose validity could not be studied through factor analysis, given the number of individuals of the sample,. Another limitation is related to data generalizability, because the study was conducted with men served in one municipality of the country, whose characteristics may be inherent to that region. It is expected that further studies adopt longitudinal, multi-center methods, with larger sample size, thus allowing the verification of the hypotheses established in this study.

\section{Conclusion}

This study assessed self-efficacy, psychological morbidity (anxiety and depression), and knowledge about postoperative care in prostatectomy patients, identifying the relationships between variables and predictors of self-efficacy. Good level of general and perceived self-efficacy was found among patients and reduced percentage of depression, which can be justified by the large proportion of men that are married or in a stable relationship.

A significant difference was observed for knowledge about postoperative care according to waiting time for surgery and anxiety due to employment situation. Psychological morbidity related negatively 
with self-efficacy, being a negative predictor for selfefficacy. Thus, it is crucial that professionals favor the development of the patient's self-efficacy, advising them properly and empowering them, so they become active in their rehabilitation and minimize psychological morbidity.

It is hoped that these findings enable the production of the patients' profile on the psychological needs after radical prostatectomy, so nurses act holistically, considering not only the need for care of physical nature, but also of psychosocial nature. Given the scarcity of studies found, carrying out other researches on the issue is necessary, especially in the assessment of knowledge about postoperative care and psychological variables, and the impact of these variables on the possible complications from surgery.

\section{References}

1. Knoll N, Scholz U, Burkert S, Roigas J, Gralla O. Effects of received and mobilized support on recipients' and providers' self-efficacy beliefs: A 1 year follow-up study with patients receiving radical prostatectomy and their spouses. Int J Psychol. 2009;44(2):129-37.

2. Inman DM, Maxson PM, Johnson KM, Myers RP, Holland DE. The impact of follow-up educational telephone calls on patients after radical prostatectomy: Finding value in low-margin activities. Urol Nurs. 2011;31(2):83-91.

3. Mehnert A, Lehmann C, Graefen M, Huland H, Koch $U$. Depression, anxiety, post-traumatic stress disorder and health-related quality of life and its association with social support in ambulatory prostate cancer patients. Eur J Cancer Care. 2010;19(1):736-45.

4. Botega NJ, Pondé MP, Medeiros P, Lima MG, Guerreiro CAM. Validação da escala hospitalar de ansiedade e depressão (HADS) em pacientes epilépticos ambulatoriais. J Bras Psiquiatr. 1998;47(6):285-9.

5. Korfage IJ, Essink-Bot ML, Janssens ACJW, Schroder $\mathrm{FH}$, Koning $\mathrm{HJ}$. Anxiety and depression after prostate cancer diagnosis and treatment: 5-year follow-up. $\mathrm{Br}$ J Cancer. 2006;94:1093-98.

6. Weber BA, Roberts BL, Yarandi $\mathrm{H}_{\text {, }}$, Mills TL, Chumbler NR, Wajsman Z. The impact of dyadic social support on self-efficacy and depression after radical prostatectomy. J Aging Health. 2007;19(4):630-45.

7. Weber BA, Roberts BL, Mills TL, Chumbler NR, Algood CB. Physical and Emotional Predictors of Depression After Radical Prostatectomy. Am J Mens Health. 2008;2(2):165-71.
8. Ministério da Saúde (BR). Estimativa 2012 - Incidência de Câncer no Brasil: Síntese de Resultados e Comentários [Internet]. Rio de Janeiro (RJ): Instituto Nacional de Câncer; 2011. [acesso 5 abril 2013]. Disponível em: http://www.inca.gov.br/estimativa/2012/index.asp

9. Humphreys MR, Fernandes KA, Sridhar SS. Impact of age at diagnosis on outcomes in men with castrateresistant prostate cancer. J Cancer. [Internet]. 2013 [acesso 2 de junho 2013];4(4):304-14. Disponível em: http://www.ncbi.nlm.nih.gov/pmc/articles/PMC3619091/ pdf/jcav04p0304.pdf

10. Harden J, Northouse L, Cimprich B, Pohl JM, Liang J, Kershaw $\mathrm{T}$. The influence of developmental life stage on quality of life in survivors of prostate cancer and their partners. J Cancer Surviv. 2008;2(2):84-94.

11. Bandura, A. Self-efficacy: toward a unifying theory of behavioral change. Psychol Rev. 1977;84(2):191-215. 12. Bandura A. Social foundations of thought and action: A social cognitive theory. Englewood: N.J. Prentice Hall; 1986. $617 \mathrm{p}$.

13. Mystakidou K, Tsilika E, Parpa E, Gogou P, Panagiotou I, Vassiliou I et al. Relationship of general self-efficacy with anxiety, symptom severity and quality of life in cancer patients before and after radiotherapy treatment. Psycho-Oncol. 2013;22(5):1089-95.

14. Razera APR, Braga EM. A importância da comunicação durante o período de recuperação pós-operatória. Rev Esc Enferm USP. 2011;45(3):632-7.

15. Santos MA, Rossi LA, Paiva L, Dantas RAS, Pompeo DA, Machado ECB. Medida da ansiedade e depressão em pacientes no pré-operatório de cirurgias eletivas. Rev Eletr Enferm. [Internet]. 2012. [acesso 31 maio 2013];14(4):922-7. Disponível em: http://www.fen. ufg.br/revista/v14/n4/v14n4a21.htm

16. Iyigun $\mathrm{E}$, Ayhan $\mathrm{H}$, Tastan S. Perceptions and experiences after radical prostatectomy in Turkish men: a descriptive qualitative study. Appl Nurs Res. 2011;24(2):101-9.

17. Bertolucci PH, Brucki SM, Campacci SR, Juliano Y. O mini-exame do estado mental em uma população geral: impacto da escolaridade. Arq Neuropsiquiatr. 1994;52:1-7.

18. Schwarzer R, Jerusalem M. Generalized Self-Efficacy scale. In: Weinman J, Wright S, Johnston M. Measures in health psychology: A user's portfolio. Causal and control beliefs. Windsor (UK): Nfer-Nelson; 1995. p. 35-7.

19. Souza I, Souza MA. Validação da Escala de Autoeficácia Geral Percebida. Rev Univ Rural: Serie Ciências Humanas. 2004; 26(1-2):12-7. 
20. Zigmond A, Snaith RP. The Hospital Anxiety and Depression Scale. Acta Psychiatr Scand 1983;67(6):361-70.

21. Botega NJ, Bio MR, Zomignani MA, Garcia JRC, Pereira WAB. Transtornos do humor em enfermaria de clínica médica e validação de escala de medida (HADS) de ansiedade e depressão. Rev Saúde Pública. 1995;29(5):355-63.

22. Ajzen $I_{;}$, Fishbein M. Understanding attitudes and predicting social. Behaviour. Englewood Cliffs: NJ. Prentice-Hall; 1980.

23. Leitzmann MF, Rohrmann S. Risk factors for the onset of prostatic cancer: age, location, and behavioral correlates. Clin Epidemiol. 2012;4:1-11.

24. Rhoden EL, Averbeck MA. Câncer de próstata localizado. Rev AMRIGS. 2010;54(1):92-9.

25. Gore JL, Gollapudi K, Bergman J, Kwan L, Krupski $\mathrm{TL}$, Litwin MS. Correlates of Bother Following Treatment for Clinically Localized Prostate Cancer. J Urol. 2010;184(4):1309-15.

26. Hamm MP, Chisholm A, Shulhan J, Milne A, Scott SD, Given LM, et al. Social media use among patients and caregivers: a scoping review. BMJ Open [Internet]. 2013. [acesso 5 ago 2013];3:01-9. Disponível em: http:// www.ncbi.nlm.nih.gov/pmc/articles/PMC3651969/pdf/ bmjopen-2013-002819.pdf

27. Fredericks S, Guruge S, Sidani S, Wan T, Un R. Postoperative patient education: a systematic review. Clin Nurs Res.2010;19(2):144-64.

28. Chambers SK, Schover L, Halford K, Clutton S, Ferguson M, Gordon L, et. al. ProsCan for Couples: Randomised controlled trial of a couples based sexuality intervention for men with localized prostate cancer who receive radical prostatectomy. BMC Cancer. [Internet]. 2008. [acesso 15 dez 2014];8:226. Disponível em: http://www.ncbi.nlm. nih.gov/pmc/articles/PMC2529334/?report=reader

29. Bicalho MB, Lopes MHBM. Impacto da incontinência urinária na vida de esposas de homens com incontinência: revisão integrativa. Rev Esc Enferm USP. 2012;46( 4):1009-14. 